\title{
Patients with atrial fibrillation undergoing total joint arthroplasty increase hospital burden.
}

\section{Vinay K Aggarwal}

The Rothman Institute of Orthopedics at Thomas Jefferson University Hospital

Eric H Tischler

The Rothman Institute of Orthopedics at Thomas Jefferson University Hospital

Zachary D Post

The Rothman Institute of Orthopedics at Thomas Jefferson University Hospital

Ian Kane

The Rothman Institute of Orthopedics at Thomas Jefferson University Hospital

Fabio R Orozco

The Rothman Institute of Orthopedics at Thomas Jefferson University Hospital Follow this and additional works at: https://jdc.jefferson.edu/rothman_institute

Part of the Orthopedics Commons

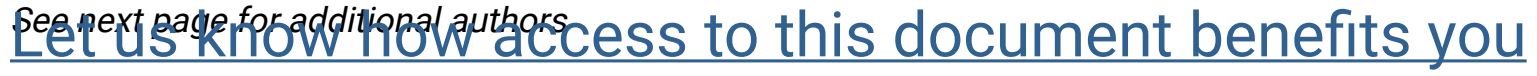

\section{Recommended Citation}

Aggarwal, Vinay K; Tischler, Eric H; Post, Zachary D; Kane, Ian; Orozco, Fabio R; and Ong, Alvin, "Patients with atrial fibrillation undergoing total joint arthroplasty increase hospital burden." (2013). Rothman Institute Faculty Papers. Paper 40.

https://jdc.jefferson.edu/rothman_institute/40

This Article is brought to you for free and open access by the Jefferson Digital Commons. The Jefferson Digital Commons is a service of Thomas Jefferson University's Center for Teaching and Learning (CTL). The Commons is a showcase for Jefferson books and journals, peer-reviewed scholarly publications, unique historical collections from the University archives, and teaching tools. The Jefferson Digital Commons allows researchers and interested readers anywhere in the world to learn about and keep up to date with Jefferson scholarship. This article has been accepted for inclusion in Rothman Institute Faculty Papers by an authorized administrator of the Jefferson Digital Commons. For more information, please contact: JeffersonDigitalCommons@jefferson.edu. 


\section{Authors}

Vinay K Aggarwal, Eric H Tischler, Zachary D Post, lan Kane, Fabio R Orozco, and Alvin Ong 


\title{
Patients with Atrial Fibrillation Undergoing Total Joint Arthroplasty Increase Hospital Burden
}

\author{
Vinay K. Aggarwal, BA, Eric H. Tischler, BA, Zachary D. Post, MD, Ian Kane, BS, Fabio R. Orozco, MD, and Alvin Ong, MD \\ Investigation performed at The Rothman Institute of Orthopedics at Thomas Jefferson University Hospital, Philadelphia, Pennsylvania
}

\begin{abstract}
Background: More than 3 million people in the United States have atrial fibrillation, most of whom are being managed with anticoagulation therapy for life. The goal of the present study was to examine the effect of chronic anticoagulation therapy on patients with atrial fibrillation who undergo total joint arthroplasty.

Methods: We retrospectively reviewed all patients undergoing aseptic primary or revision total joint arthroplasty at our facility from March 2007 to August 2011. One hundred and sixty-one patients with atrial fibrillation (Group A) were compared with 161 matched controls (Group B). A total of 112 hips and 210 knees underwent 239 primary arthroplasties and eighty-three revisions. The groups were compared with use of conditional logistic regression (with matching on the basis of the involved joint [hip or knee], type of procedure [revision or primary], age, and sex) with regard to the length of hospital stay, postoperative hemoglobin levels, transfusion requirements, and readmissions.
\end{abstract}

Results: The preoperative length of stay $(1.7$ versus 0.2 days; $p<0.0001)$, postoperative length of stay (4.6 versus 3.2 days; $p=0.0002$ ), and total length of stay ( 6.3 versus 3.4 days; $p<0.0001$ ) were significantly longer for patients with atrial fibrillation (Group A). Hemoglobin levels were lower (but not significantly so) for Group A at baseline (13.1 versus $13.8 \mathrm{mg} / \mathrm{dL}$ ), on Postoperative Day 2 (10.1 versus $10.6 \mathrm{mg} / \mathrm{dL}$ ), on Postoperative Day 3 (9.8 versus $10.2 \mathrm{mg} / \mathrm{dL}$ ), on Postoperative Day 4 (9.6 versus $10.1 \mathrm{mg} / \mathrm{dL})$, on Postoperative Day 5 (9.7 versus $9.9 \mathrm{mg} / \mathrm{dL})$, and at discharge $(9.9$ versus $10.3 \mathrm{mg} / \mathrm{dL}$ ). Group A had a significantly higher prevalence of blood transfusion (15.5\% versus 3.7\%; $p=0.0005$ ) and periprosthetic joint infection (5.6\% versus $0.62 \% ; p=0.0196)$. A diagnosis of atrial fibrillation (odds ratio, $4.09 ; 95 \%$ confidence interval, 2.05 to $8.18 ; p<0.0001$ ) significantly increased the odds of total joint arthroplasty complication and the need for hospital readmission.

Conclusions: Patients with preoperative atrial fibrillation undergoing total joint arthroplasty had an increased length of hospital stay, increased transfusion requirements, and an increased risk of periprosthetic joint infection and unplanned hospital readmission.

Level of Evidence: Prognostic Level II. See Instructions for Authors for a complete description of levels of evidence.

A trial fibrillation is the most common chronic cardiac arrhythmia in the United States, occurring in an estimated 3.2 million people in $2005^{1,2}$. It has been projected that by the year 2050, the number of Americans with atrial fibrillation will increase to almost 8 million $^{2}$. The prevalence of this cardiac dysrhythmia increases dramatically in the elderly population, to $9.0 \%$ in persons eighty years of age or older ${ }^{3}$. At a time when health-care costs are increasingly scrutinized, the economic and health-care burdens of patients with atrial fibrillation are approximately five times those of patients without atrial fibrillation ${ }^{4}$. In 2005, an estimated $\$ 6.65$ billion was spent on the treatment of patients who have this condition in the United States ${ }^{5}$.

Much of this health-care burden is due to the additional medical utilization associated with chronic anticoagulation therapy, which is lifelong for most individuals with atrial fibrillation ${ }^{6,7}$. The American College of Chest Physicians (ACCP) recommends that patients with atrial fibrillation receive high-dose aspirin or

Disclosure: None of the authors received payments or services, either directly or indirectly (i.e., via his or her institution), from a third party in support of any aspect of this work. One or more of the authors, or his or her institution, has had a financial relationship, in the thirty-six months prior to submission of this work, with an entity in the biomedical arena that could be perceived to influence or have the potential to influence what is written in this work. No author has had any other relationships, or has engaged in any other activities, that could be perceived to influence or have the potential to influence what is written in this work. The complete Disclosures of Potential Conflicts of Interest submitted by authors are always provided with the online version of the article. 


\begin{tabular}{|c|c|c|c|}
\hline Demographic Variables & $\begin{array}{l}\text { Atrial Fibrillation } \\
\text { Group }(\mathrm{N}=161)\end{array}$ & Control Group $(\mathrm{N}=161)$ & $\mathrm{P}$ Value \\
\hline Age* $(y r)$ & 72.8 & 69.0 & 0.03 \\
\hline $\mathrm{BMI} *\left(\mathrm{~kg} / \mathrm{m}^{2}\right)$ & 31.2 & 30.4 & 0.589 \\
\hline \multicolumn{4}{|l|}{ Index procedure } \\
\hline
\end{tabular}

*The values are given as the mean.

warfarin anticoagulation therapy, depending on their risk factors for a thrombotic event ${ }^{8,9}$. For patients receiving warfarin, the international normalized ratio (INR) is kept in the range from 2.0 to 3.0, placing elderly patients at a major risk for bleeding events such as intracranial hemmorhage ${ }^{10}$. In addition, patients receiving anticoagulation therapy who have surgery are at increased risk for persistent wound drainage and hematoma formation ${ }^{11}$.

These issues pose major problems for patients with chronic atrial fibrillation who undergo total joint arthroplasty. While adequate anticoagulation therapy is required for these patients to prevent thrombotic events such as cerebrovascular accident, the elevated INR required in these patients puts them at considerable risk for bleeding ${ }^{12}$. It is well established that bleeding complications create an increased potential for delayed woundhealing, functional disability, and periprosthetic joint infec$\operatorname{tion}^{11,13}$. To minimize these risks, patients with atrial fibrillation are sometimes admitted to the hospital prior to surgery in order to wean them from anticoagulation therapy and to normalize INR levels ${ }^{14-16}$. The additional care provided for patients with atrial fibrillation even after total joint arthroplasty may pose a substantial increase in the health-care burden. We are aware of no study that has examined this subset of patients undergoing arthroplasty.

The primary goal of our case-controlled study was to examine the effect of atrial fibrillation and chronic anticoagulation therapy on hospital burden for patients undergoing total joint arthroplasty. Outcome measures evaluated included the length of stay in the hospital, postoperative anemia, blood transfusion requirements, and hospital readmission due to surgery-related complications.

\section{Materials and Methods}

$W_{\text {of cases and matched controls. Using our institutional electronic database, }}^{\text {e performed a retrospective case-controlled study with a one-to-one ratio }}$ we identified all patients with a preexisting diagnosis of atrial fibrillation undergoing aseptic primary or revision total hip or knee arthroplasty at our institution during a four-year span from March 2007 to September 2011. More than 3000 total joint arthroplasty procedures were performed at the institution during the study period.

For each patient with atrial fibrillation, we aimed to identify one matching patient without atrial fibrillation as a control. This control population was derived with use of our electronic database by matching for the following variables: age, sex, involved joint (hip or knee), laterality, procedure type (primary or revision), body mass index (BMI), surgeon, postoperative prophylaxis against deep-vein thrombosis, and approximate date of surgery. Matched variables were chosen to eliminate their potential confounding effects on study outcomes. Revision was defined as partial or complete removal or exchange of the components. The exclusion criteria were bilateral total joint arthroplasty, revision for the treatment of infection at the site of the total joint arthroplasty, or less than six months of followup after the procedure of interest.

All arthroplasties in both patient groups were performed from 2007 to 2011 by two senior surgeons (A.O. and F.R.O.) at a single, high-volume institution. Preoperatively, all patients with atrial fibrillation were receiving either anticoagulation therapy with warfarin (used for approximately $90 \%$ of patients with atrial fibrillation) or other chronic therapy with aspirin, clopidogrel, or dabigatran (used for approximately $10 \%$ of patients with atrial fibrillation). The institutional hospital protocol was to preadmit all patients with atrial fibrillation who were receiving chronic warfarin therapy one day prior to surgery in order to ensure a normal INR level. Once warfarin was discontinued, these patients were managed with heparin bridging until six hours before surgery. Patients receiving alternative chronic treatment for atrial fibrillation were asked not to take medication at least seven days prior to surgery but were not admitted to the hospital prior to the date of surgery. All patients in both the study and control groups were managed with warfarin for anticoagulation after surgery.

Overall, 161 joints (fifty-five hips and 106 knees) in 161 consecutive patients with atrial fibrillation were matched with 161 joints (fifty-seven hips and 104 knees) in 161 control patients without atrial fibrillation. There were eighty-one men $(50.3 \%)$ in the atrial fibrillation group and eighty-seven men

\begin{tabular}{|lcc|}
\hline $\begin{array}{c}\text { TABLE II Reasons for Readmission in Patients with and without } \\
\text { Atrial Fibrillation* }\end{array}$ & $\begin{array}{c}\text { Atrial Fibrillation } \\
\text { Group }\end{array}$ & $\begin{array}{c}\text { Control } \\
\text { Group }\end{array}$ \\
\hline Reason for Readmission & 9 & 1 \\
\hline Periprosthetic joint infection & 7 & 1 \\
Wound complication & 8 & 7 \\
Mechanical joint failure & 7 & 1 \\
Cardiopulmonary event & 4 & 0 \\
Gastrointestinal complication & 4 & 0 \\
Atrial fibrillation episode & 2 & 0 \\
Other & 41 & 10 \\
Total & & \\
\hline *The values are given as the number of patients. & \\
\hline
\end{tabular}


The Journal of Bone \& Joint Surgery $\cdot$ Jbjs.org Volume 95-A • Number $17 \cdot$ September 4, 2013
Patients with Atrial Fibrillation Undergoing Total Joint Arthroplasty InCrease Hospital Burden

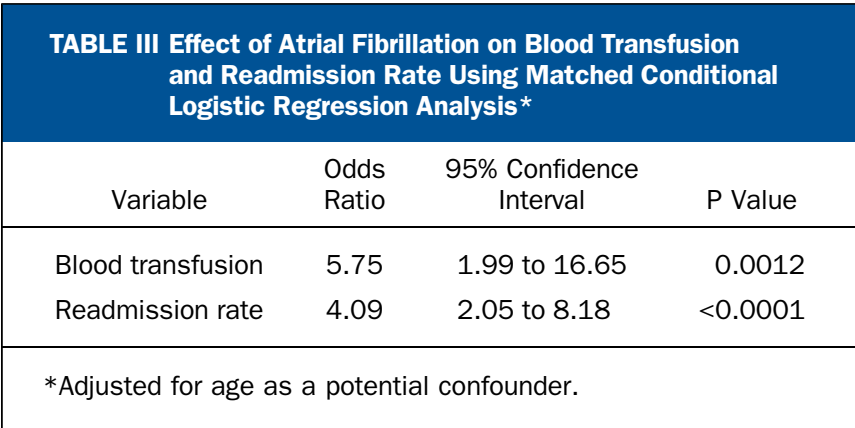

(54.0\%) in the control group. The mean age was 72.8 years for the atrial fibrillation group and 69.0 years for the control group. The mean BMI was 31.2 for the atrial fibrillation group and 30.4 for the control group. There were 123 primary procedures $(76.4 \%)$ and thirty-eight revision procedures $(23.6 \%)$ in the atrial fibrillation group, compared with 116 primary procedures $(72.0 \%)$ and forty-five revision procedures $(28.0 \%)$ in the control group. The baseline characteristics other than age were not significantly different between the two groups (Table I).

A thorough chart review utilizing electronic medical records was used to ascertain information regarding outcomes of interest. The primary outcome of our study analysis was hospital burden as measured on the basis of preoperative, postoperative, and total length of stay. The preoperative length of stay was defined as the interval between hospital admission and surgery start time, the postoperative length of stay was defined as the interval between surgery start time and hospital discharge time, and the total length of stay was defined as the interval between hospital admission and hospital discharge time. The presence of postoperative anemia was assessed through the measurement of hemoglobin ( $\mathrm{Hgb})$ levels at baseline (prior to surgery), on Postoperative Days 1 through 5, and on the day of discharge. Additionally, the INR at the time of discharge was recorded for the evaluation of anticoagulation therapy and bleeding risk in both groups. Blood transfusion requirements were recorded as binary variables based on the need for allogeneic postoperative red blood cell transfusion as compared with no need for transfusion. Finally, complications and readmissions following discharge from the hospital for reasons related to the surgical procedure or the diagnosis of atrial fibrillation were obtained from a review of medical records. Means and frequencies were calculated for continuous and categorical variables, respectively. The length of hospital stay was reported as the mean and the standard deviation (in days). Hemoglobin levels were reported as the mean (in $\mathrm{mg} / \mathrm{dL}$ ). The need for blood transfusion and the readmission rate were modeled with use of conditional logistic regression. Conditional logistic regression was used as all patients were matched for potentially confounding variables of joint (hip or knee), age, sex, and procedure (primary or revision).

\section{Source of Funding}

No external funding was received for this study.

\section{Results}

The preoperative, postoperative, and total lengths of stay I were all significantly associated with the diagnosis of preexisting atrial fibrillation. The mean preoperative length of stay (and standard deviation) was $1.7 \pm 0.7$ days for patients with atrial fibrillation and $0.2 \pm 0.2$ day for patients without atrial fibrillation $(\mathrm{p}<0.0001)$. The mean postoperative length of stay was $4.6 \pm 4.6$ days for patients with atrial fibrillation and $3.2 \pm$ 1.1 days for patients without atrial fibrillation $(\mathrm{p}=0.0002)$. The mean total length of stay was $6.3 \pm 4.7$ days for patients with atrial fibrillation and $3.4 \pm 1.1$ days for patients without atrial fibrillation $(\mathrm{p}<0.0001)$.

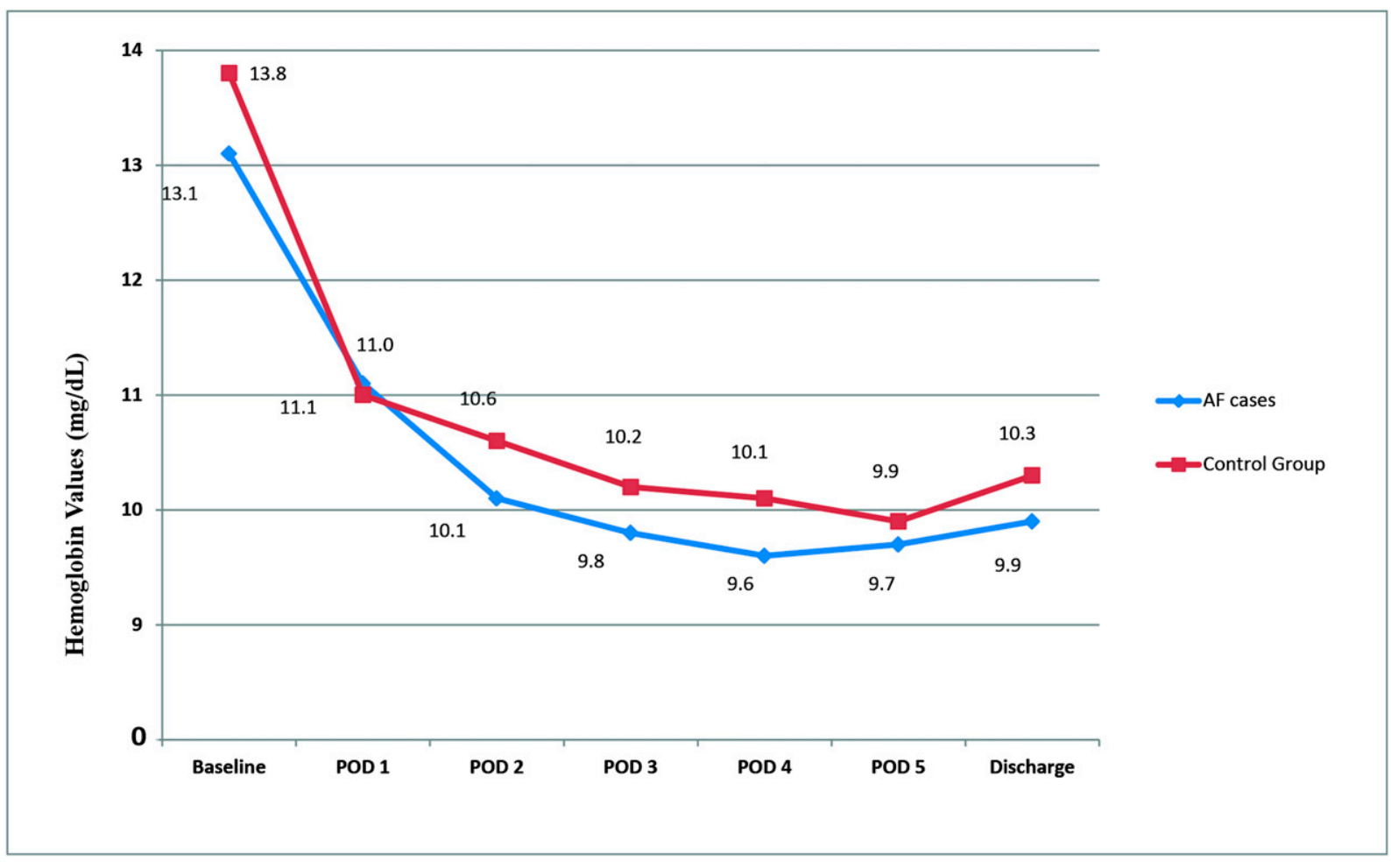

Fig. 1

Line graph showing that the mean hemoglobin level for patients with atrial fibrillation (AF) was slightly lower on all days of hospitalization except for Postoperative Day (POD) 1. No differences reached significance. 
TABLE IV Complications Following Total Joint Arthroplasty

\begin{tabular}{|lccc|}
\hline Complication Category & Atrial Fibrillation Group* & Control Group* & Palue \\
\hline Periprosthetic joint & 9 & 1 & 0.0196 \\
infection & 12 & 6 & 0.2244 \\
Cardiovascular & 7 & 2 & 0.1735 \\
Wound & 7 & 0 & 0.0146 \\
Bleeding event & 11 & 7 & 0.4678 \\
Mechanical joint & & 0 & 0.0606 \\
failure & 5 & 2 & 0.0199 \\
Sepsis/cardiogenic shock & 11 & 18 & $<0.0001$ \\
Other & 62 & & \\
Total & & & \\
\hline
\end{tabular}

*The values are given as the number of patients.

The mean hemoglobin levels on the day of admission (baseline), on Postoperative Days 1 through 5, and on the day of discharge did not differ significantly between the groups (Fig. 1). At the time of discharge, the INR for patients with atrial fibrillation was nontherapeutic and was not significantly different from that for patients without atrial fibrillation ( 1.8 versus $1.7 ; \mathrm{p}=0.1176)$.

The prevalence of blood transfusion was $15.5 \%$ (twentyfive of 161) for patients with atrial fibrillation and 3.7\% (six of 161) for patients without atrial fibrillation $(\mathrm{p}=0.0005)$. Fortyone $(25.5 \%)$ of the 161 patients with atrial fibrillation had an unplanned readmission related to surgery, whereas just ten $(6.2 \%)$ of the 161 patients without atrial fibrillation were readmitted $(\mathrm{p}<0.0001)$ (Table II). A diagnosis of atrial fibrillation increased the odds of blood transfusion by 5.75 times (95\% confidence interval $[\mathrm{CI}], 1.99$ to 16.65$)(\mathrm{p}=0.0012)$ and increased the odds of unplanned readmission by 4.09 times (95\% CI, 2.05 to 8.18) ( $\mathrm{p}<0.0001)$ (Table III).

The overall rate of complications related to total joint arthroplasty surgery was significantly greater in the atrial fibrillation group $(38.5 \%$ versus $11.2 \%$; $<0.0001)$. Table IV shows all complications in both groups by category. Cardiovascular complications included hypotension, bradycardia, tachycardia, congestive heart failure, arrhythmic episode, or myocardial infarction requiring some form of acute in-hospital treatment. Wound-related complications included hematoma formation, dehiscence, cellulitis, or superficial infection. Mechanical joint complications included arthrofibrosis, aseptic prosthetic loosening, joint instability, and knee extensor mechanism failure. Bleeding events included hematuria, gastrointestinal bleeding, and blood in the stool. Of the five patients in the atrial fibrillation group who experienced septic or cardiogenic shock, two died. The "other" category included painful paresthesias, urinary retention, urinary tract infection, postoperative pneumonia, and gastrointestinal upset.

\section{Discussion}

A trial fibrillation is a common cardiac comorbidity that carries a one-in-four lifetime risk of development for both men and women forty years of age and older ${ }^{1}$. This condition predominantly affects the elderly, with a mean age of 66.8 years in men and 74.6 years in women ${ }^{17}$. Kurtz et al. reported that the demand for all arthroplasty procedures is projected to grow dramatically over the next several decades ${ }^{18,19}$. Their analysis showed that elderly patients in the sixty-five to eighty-four-yearold age group are expected to have considerably higher rates of total joint arthroplasty procedures than younger patients are. We are aware of no studies regarding the additional costs associated with the management of patients with atrial fibrillation who undergo total joint arthroplasty. The purpose of the present study was to evaluate this increased health-care burden with use of a case-controlled matched study of patients at our institution.

Our study illustrates the considerable additional economic cost associated with caring for patients with preexisting atrial fibrillation who undergo total joint arthroplasty. The mean preoperative, postoperative, and total lengths of stay were significantly longer in this group. Other medical specialties have reported on hospital stay and associated costs for patients with atrial fibrillation. In a cohort of patients hospitalized with atrial fibrillation as a secondary discharge diagnosis, Song et al. showed a similar increase in the mean length of stay (1.84 days longer) and hospital cost ( $\$ 3146$ greater $)^{7}$. In patients undergoing coronary artery bypass surgery, several studies have identified atrial fibrillation as a strong independent predictor of hospital stay prolongation after surgery ${ }^{6,20}$. These findings are all in agreement with the analysis of our data. However, those studies highlight the complications that can occur as the result of an episode of atrial fibrillation in the hospital and do not focus on the surgical risks and considerations pertaining to patients with preexisting atrial fibrillation.

A major reason for the increased hospital burden associated with patients with atrial fibrillation who undergo total joint arthroplasty is the delicate balance of their anticoagulation therapy. Not only does it take almost four days for the antithrombotic effect of warfarin to recede, but three days are also typically required to reestablish therapeutic anticoagulation after resuming the medication ${ }^{16}$. Although not universally practiced across the 
The Journal of Bone \& Joint Surgery • Jbjs. org Volume 95-A · Number 17 -September 4, 2013
Patients with atrial Fibrillation Undergoing Total Joint Arthroplasty Increase Hospital Burden country, at our institution we preadmit patients who are receiving anticoagulation therapy in order to ensure that a safe INR is obtained for surgery. The ACCP guidelines for patients with atrial fibrillation who require temporary interruption in warfarin therapy state that bridging anticoagulation with heparin is recommended for patients with high thromboembolic risk or for those undergoing high-risk procedures ${ }^{21}$. Although many consider total joint arthroplasty to be a procedure that is associated with a high risk of thrombotic and bleeding events, Chana et al. and Rhodes et al. suggested that interruption of warfarin therapy is not required during joint arthroplasty and does not lead to a higher rate of complications $s^{22,23}$. As these were both small retrospective studies with few patients (twenty-four and thirty-eight patients, respectively), we suggest that larger clinical trials in patients undergoing total joint arthroplasty will provide more definitive guidance for perioperative anticoagulation management of patients who have atrial fibrillation ${ }^{24}$.

The management of patients who have atrial fibrillation and undergo total joint arthroplasty is burdensome not only because of the increased length of stay in the hospital associated with anticoagulation but also because of risks associated with greater postoperative bleeding. In the present study, increased bleeding was reflected by postoperative anemia and higher blood transfusion rates. Parvizi et al. reported that excessive postoperative bleeding complications, such as hematoma formation and wound drainage, were significant risk factors for the development of periprosthetic joint infection ${ }^{11}$. In addition, Pulido et al. found that allogeneic blood transfusion after surgery was an independent predisposing risk factor for periprosthetic joint infection, with an odds ratio $(\mathrm{OR})$ of $2.11(\mathrm{p}=0.02)^{25}$. While it was beyond the scope of the present study to analyze the direct correlation between blood loss or transfusion and periprosthetic joint infection, we did find that the prevalence of periprosthetic joint infection was $5.6 \%$ (nine of 161) in the atrial fibrillation group, compared with $0.62 \%$ (one of 161 ) in the control group ( $\mathrm{p}=$ 0.0196). To demonstrate the dangers of blood loss further, the use of allogeneic blood transfusion also has been linked to a 3.5-times greater likelihood of admission to the intensive care unit after total joint arthroplasty ${ }^{26}$.

We found that a diagnosis of atrial fibrillation significantly increased the odds of hospital readmission after discharge following total joint arthroplasty (OR, 4.09; 95\% CI, 2.05 to 8.18). In the present health-care environment, reimbursements will soon be tied to high-quality, efficient care, otherwise known as pay-for-performance. Orthopaedic surgeons who perform total joint arthroplasty and whose practice includes patients with atrial fibrillation may be adversely affected by the increased rate of unplanned readmission that we found. Rather than deny joint reconstruction procedures to this patient population, surgeons must instead focus on the prevention of complications. A com- mentary by Bozic et al. suggested that with newer reimbursement policies in orthopaedic practices, medical treatment may suffer because of inevitable health-care provider gaming and patient deselection, placing the burden on lower-tier, lower-quality providers $^{27}$. Our goal in presenting this study is to highlight the issues that orthopaedic surgeons face when patients with atrial fibrillation are candidates for total joint arthroplasty.

The limitations of the present study are inherent to its retrospective design. Because the majority of our patients were receiving warfarin for the treatment of chronic atrial fibrillation, we were unable to evaluate the effect of newer medications such as dabigatran on the postoperative parameters studied. Nonetheless, our study is in accordance with previous literature on the challenges that patients with atrial fibrillation pose as the population continues to age. In addition, we utilized a matched casecontrolled study design to ensure that we accounted for as many potentially confounding risk factors as possible. One additional limitation is that because all arthroplasties were limited to one institution and were performed by only two surgeons, it may be difficult to generalize the results from our analysis. However, our homogenous patient population and standardized surgical protocol ensured a reliable comparison between the two patient groups being examined. Finally, because of a lack of literature surrounding this topic, we were unable to make direct comparisons with other studies of patients with preexisting atrial fibrillation who underwent total joint arthroplasty.

In conclusion, patients with preoperative atrial fibrillation who underwent total joint arthroplasty at our institution had increased length of hospital stay, increased postoperative anemia and transfusion requirements, and an increased risk of complications and unplanned readmissions. As complications and readmissions can negatively affect hospital and physician reimbursement, we recommend increased surveillance of these patients with atrial fibrillation to appropriately manage expectations and to decrease complication rates.

Vinay K. Aggarwal, BA

Eric H. Tischler, BA

Zachary D. Post, MD

Ian Kane, BS

Fabio R. Orozco, MD

Alvin Ong, MD

The Rothman Institute of Orthopedics

at Thomas Jefferson University Hospital, 925 Chestnut Street,

2nd Floor, Philadelphia, PA 19107.

E-mail address for V.K. Aggarwal: vinayagg1@gmail.com.

E-mail address for A. Ong: Alvin.Ong@rothmaninstitute.com

\section{References}

1. Lloyd-Jones DM, Wang TJ, Leip EP, Larson MG, Levy D, Vasan RS, D’Agostino RB, Massaro JM, Beiser A, Wolf PA, Benjamin EJ. Lifetime risk for development of atrial fibrillation: the Framingham Heart Study. Circulation. 2004 Aug 31;110(9): 1042-6. Epub 2004 Aug 16.
2. Naccarelli GV, Varker H, Lin J, Schulman KL. Increasing prevalence of atrial fibrillation and flutter in the United States. Am J Cardiol. 2009 Dec 1;104(11):1534-9. 3. Go AS, Hylek EM, Phillips KA, Chang Y, Henault LE, Selby JV, Singer DE. Prevalence of diagnosed atrial fibrillation in adults: national implications for rhythm 
The Journal of Bone \& Joint Surgery $\cdot$ Jbjs.org Volume 95-A · Number $17 \cdot$ September 4, 2013
Patients with Atrial Fibrillation Undergoing Total Joint Arthroplasty Increase Hospital Burden management and stroke prevention: the AnTicoagulation and Risk Factors in Atrial Fibrillation (ATRIA) Study. JAMA. 2001 May 9;285(18):2370-5.

4. Wu EQ, Birnbaum HG, Mareva M, Tuttle E, Castor AR, Jackman W, Ruskin J. Economic burden and co-morbidities of atrial fibrillation in a privately insured population. Curr Med Res Opin. 2005 Oct;21(10):1693-9.

5. Coyne KS, Paramore C, Grandy S, Mercader M, Reynolds M, Zimetbaum P. Assessing the direct costs of treating nonvalvular atrial fibrillation in the United States. Value Health. 2006 Sep-Oct;9(5):348-56.

6. Tamis JE, Steinberg JS. Atrial fibrillation independently prolongs hospital stay after coronary artery bypass surgery. Clin Cardiol. 2000 Mar;23(3):155-9.

7. Song $X$, Sander SD, Johnson BH, Varker H, Amin AN. Impact of atrial fibrillation and oral anticoagulation on hospital costs and length of stay. Am J Health Syst Pharm. 2012 Feb 15;69(4):329-38.

8. Wann LS, Curtis AB, January CT, Ellenbogen KA, Lowe JE, Estes NA 3rd, Page RL, Ezekowitz MD, Slotwiner DJ, Jackman WM, Stevenson WG, Tracy CM, Fuster V, Rydén LE, Cannom DS, Le Heuzey JY, Crijns HJ, Lowe JE, Curtis AB, Olsson S, Ellenbogen KA, Prystowsky EN, Halperin JL, Tamargo JL, Kay GN, Wann L, Jacobs AK, Anderson JL, Albert N, Hochman JS, Buller CE, Kushner FG, Creager MA, Ohman EM, Ettinger SM, Stevenson WG, Guyton RA, Tarkington LG, Halperin JL, Yancy CW; 2011 Writing Group Members; 2006 Writing Committee Members; ACCF/AHA Task Force Members. 2011 ACCF/AHA/HRS focused update on the management of patients with atrial fibrillation (updating the 2006 guideline): a report of the American College of Cardiology Foundation/American Heart Association Task Force on Practice Guidelines. Circulation. 2011 Jan 4;123(1):104-23. Epub 2010 Dec 20.

9. Singer DE, Albers GW, Dalen JE, Fang MC, Go AS, Halperin JL, Lip GY, Manning WJ; American College of Chest Physicians. Antithrombotic therapy in atrial fibrillation: American College of Chest Physicians Evidence-Based Clinical Practice Guidelines (8th Edition). Chest. 2008 Jun:133(6 Suppl):546S-592S.

10. Fang MC, Chang Y, Hylek EM, Rosand J, Greenberg SM, Go AS, Singer DE. Advanced age, anticoagulation intensity, and risk for intracranial hemorrhage among patients taking warfarin for atrial fibrillation. Ann Intern Med. 2004 Nov 16;141(10):745-52.

11. Parvizi J, Ghanem E, Joshi A, Sharkey PF, Hozack WJ, Rothman RH. Does “excessive" anticoagulation predispose to periprosthetic infection? J Arthroplasty. 2007 Sep;22(6)(Suppl 2):24-8. Epub 2007 Jul 26.

12. Pellegrini VD Jr, Sharrock NE, Paiement GD, Morris R, Warwick DJ. Venous thromboembolic disease after total hip and knee arthroplasty: current perspectives in a regulated environment. Instr Course Lect. 2008;57:637-61.

13. Cheung EV, Sperling JW, Cofield RH. Infection associated with hematoma formation after shoulder arthroplasty. Clin Orthop Relat Res. 2008 Jun;466(6):1363-7. Epub 2008 Apr 18.

14. Jafri SM, Mehta TP. Periprocedural management of anticoagulation in patients on extended warfarin therapy. Semin Thromb Hemost. 2004 Dec;30(6): 657-64.

15. Krahn AD, Healey JS, Simpson CS, Essebag V, Sivakumaran S, Birnie DH. Anticoagulation of patients on chronic warfarin undergoing arrhythmia device sur- gery: wide variability of perioperative bridging in Canada. Heart Rhythm. 2009 Sep;6(9):1276-9. Epub 2009 Jun 06.

16. Kearon $\mathrm{C}$, Hirsh J. Management of anticoagulation before and after elective surgery. N Engl J Med. 1997 May 22;336(21):1506-11.

17. Roger VL, Go AS, Lloyd-Jones DM, Adams RJ, Berry JD, Brown TM, Carnethon MR, Dai S, de Simone G, Ford ES, Fox CS, Fullerton HJ, Gillespie C, Greenlund KJ, Hailpern SM, Heit JA, Ho PM, Howard VJ, Kissela BM, Kittner SJ, Lackland DT, Lichtman JH, Lisabeth LD, Makuc DM, Marcus GM, Marelli A, Matchar DB, McDermott MM, Meigs JB, Moy CS, Mozaffarian D, Mussolino ME, Nichol G, Paynter NP, Rosamond WD, Sorlie PD, Stafford RS, Turan TN, Turner MB, Wong ND, WylieRosett J; American Heart Association Statistics Committee and Stroke Statistics Subcommittee. Heart disease and stroke statistics-2011 update: a report from the American Heart Association. Circulation. 2011 Feb 1;123(4):e18-209. Epub 2010 Dec 15.

18. Kurtz S, Ong K, Lau E, Mowat F, Halpern M. Projections of primary and revision hip and knee arthroplasty in the United States from 2005 to 2030. J Bone Joint Surg Am. 2007 Apr;89(4):780-5.

19. Kurtz S, Mowat F, Ong K, Chan N, Lau E, Halpern M. Prevalence of primary and revision total hip and knee arthroplasty in the United States from 1990 through 2002. J Bone Joint Surg Am. 2005 Jul;87(7):1487-97.

20. Auer J, Weber T, Berent R, Ng CK, Lamm G, Eber B. Postoperative atrial fibrillation independently predicts prolongation of hospital stay after cardiac surgery. J Cardiovasc Surg (Torino). 2005 Dec;46(6):583-8.

21. Douketis JD, Spyropoulos AC, Spencer FA, Mayr M, Jaffer AK, Eckman MH, Dunn AS, Kunz R; American College of Chest Physicians. Perioperative management of antithrombotic therapy: Antithrombotic Therapy and Prevention of Thrombosis, 9th ed: American College of Chest Physicians Evidence-Based Clinical Practice Guidelines. Chest. 2012 Feb;141(2 Suppl):e326S-50S.

22. Chana R, Salmon L, Waller A, Pinczewski L. Warfarin management in patients on continuous anticoagulation therapy undergoing total knee replacement. J Bone Joint Surg Br. 2011 Nov;93(11):1497-502.

23. Rhodes DA, Severson EP, Hodrick JT, Dunn HK, Hofmann AA. Discontinuation of warfarin is unnecessary in total knee arthroplasty. Clin Orthop Relat Res. 2010 Jan;468(1):120-6.

24. Garwood CL, Hwang JM, Moser LR. Striking a balance between the risks and benefits of anticoagulation bridge therapy in patients with atrial fibrillation: clinical updates and remaining controversies. Pharmacotherapy. 2011 Dec;31(12):1208-20. 25. Pulido L, Ghanem E, Joshi A, Purtill JJ, Parvizi J. Periprosthetic joint infection: the incidence, timing, and predisposing factors. Clin Orthop Relat Res. 2008 Jul;466(7):1710-5. Epub 2008 Apr 18.

26. Abdelsalam H, Restrepo C, Tarity TD, Sangster W, Parvizi J. Predictors of intensive care unit admission after total joint arthroplasty. J Arthroplasty. 2012 May;27(5):720-5.

27. Bozic KJ, Smith AR, Mauerhan DR. Pay-for-performance in orthopedics: implications for clinical practice. J Arthroplasty. 2007 Sep;22(6)(Suppl 2):8-12. Epub 2007 Jul 26. 